\title{
PREPARATION AND PROPERTIES OF NANOCOMPOSITES FROM PRISTINE AND MODIFIED SWCNTS OF COMPARABLE AVERAGE ASPECT RATIOS
}

\author{
J. G. Smith, Jr. ${ }^{1}$, D. M. Delozier ${ }^{2}$, K. A. Watson ${ }^{2}$, \\ J. W. Connell ${ }^{1}$, E. Bekyarova ${ }^{3}$, A. Yu ${ }^{3}$, and R. C. Haddon ${ }^{3}$ \\ ${ }^{1}$ NASA Langley Research Center, Hampton, VA 23681-2199 \\ ${ }^{2}$ National Institute of Aerospace, 100 Exploration Way, Hampton, VA 23666-6147 \\ ${ }^{3}$ University of California, Riverside, Department of Chemistry, Riverside, CA 92521
}

\begin{abstract}
Low color, flexible, space-durable polyimide films with inherent and robust electrical conductivity to dissipate electrostatic charge (ESC) have been under investigation as part of a materials development activity for future NASA space missions. The use of single-walled carbon nanotubes (SWCNTs) is one means to achieving this goal. Even though the concentration of SWCNTs needed to achieve ESC dissipation is typically low, it is dependent upon purity, size, dispersion, and functionalization. In this study, SWCNTs prepared by the electric arc discharge method were used to synthesize nanocomposites using the LaRC ${ }^{\text {TM }}$ CP2 backbone as the matrix. Pristine and functionalized SWCNTs were mixed with an alkoxysilane terminated amide acid of LaRCTM $\mathrm{CP} 2$ and the soluble imide form of the polymer and the resultant nanocomposites evaluated for mechanical, thermal, and electrical properties. Due to the preparative conditions for the pristine and functionalized SWCNTs, the average aspect ratio for both was comparable. This permitted the assessment of SWCNT functionalization with respect to various interactions (e.g. van der Waals, hydrogen bonding, covalent bond formation, etc.) with the matrix and the macroscopic effects upon nanocomposite properties. The results of this study are described herein.
\end{abstract}

Keywords: Polyimide, alkoxysilane terminated polyimides, electrical conductivity, nanocomposites

\section{INTRODUCTION}

Space environmentally durable polymeric materials (i.e., films, coating, moldings, etc.) are an enabling technology for the development of Gossamer spacecraft. These large, deployable, and ultralightweight vehicles are designed with sufficient compliance to allow for stowage in a compact container on conventional launch vehicles. After orbit is achieved, the vehicle automatically deploys to its full size, which can be many square meters. ${ }^{1}$ Two "proof-of-concept" examples of this technology are the Znamya-2 launched in 1993 and the inflatable antennae experiment deployed from the space shuttle Endeavor (STS-77) in 1996. These experimental vehicles used Mylar ${ }^{\circledR}$, or its equivalent, for the flight tests to demonstrate the concept. Due to the short duration of these space flight experiments the longterm environmental stability of the polymer was not of concern.

However, future Gossamer spacecraft will require film-based materials that are space environmentally durable to enable longer missions. Depending on the orbital location of the vehicle, the film must exhibit resistance to environmental hazards such as atomic oxygen in low Earth orbit, 
ultraviolet (UV) and vacuum UV radiation, electrons/ions, solar flare protons and galactic cosmic rays. ${ }^{2-}$

${ }^{4}$ Since polymer films are insulative, energetic particles such as electrons/ions can penetrate the material surface and deposit a charge. This electrostatic charge (ESC) accumulates over time and eventually dissipates in a single event on surrounding surfaces (i.e., films, electronics, etc.) potentially causing considerable damage. To prevent this event from occurring, it is necessary to mitigate this charge from accumulating by making the film surface conductive. This conductivity is typically measured as surface resistance with the level needed to prevent ESC accumulation in the range of $10^{6}$ to $10^{10} \Omega / \mathrm{square}$.

Many of the material property requirements for Gossamer spacecraft, with the exception of electrical conductivity, can be met using aromatic polyimides based on the appropriate choice of constituent monomers. ${ }^{5,6}$ Electrical conductivity on spacecraft surfaces has been achieved through the use of conductive coatings such as indium tin oxide (ITO). Transparency of this conductive layer is important since some mission applications require films with low solar absorptivity (synonymous with low color), optical transparency, and high thermal emissivity as well as conductivity. ITO coatings also provide transparency and low solar absorptivity but they are brittle. Folding of ITO coated films fractures the coating resulting in loss of electrical conductivity. In the early 1990's, single-walled carbon nanotubes (SWCNTs) offered a viable solution to this film conductivity issue due to their nanometer size and exceptional electrical properties. Previous work with SWCNTs [prepared by the high-pressure carbon monoxide (HiPco) process] has afforded the electrical conductivity levels (measured as resistivity) needed for electrostatic charge dissipation (ESD) with minimal effect on the optical and thermo-optical (solar absorptivity and thermal emissivity) properties of the base film. An attractive combination of properties has been attained in bulk loading of SWCNTs in the polymer ${ }^{7-9}$ and as a surface layer (e.g. Bucky paper) via spray coating. ${ }^{10-14}$ Bulk loading of the SWCNTs provides conductivity through the thickness whereas SWCNT spray coating provides surface conductivity.

The HiPco, electric arc discharge (EA), laser ablation, and chemical vapor deposition methods have been used in SWCNT preparation. ${ }^{15,16}$ The materials obtained from each of these processes possess different properties and impurities. It is known that improvements in mechanical and physical properties of a host polymer compared to the virgin material can be obtained by incorporating nanomaterials provided that the nanomaterials are uniformly dispersed throughout the matrix. However, this has been difficult to achieve with SWCNTs due to their insolubility and/or incompatibility with the host resin. SWCNTs tend to agglomerate as bundles both in solvents and the resin. Once dispersed, the SWCNTs often reagglomerate soon thereafter due to van der Waals attraction. One approach to improve SWCNT dispersability and solubility is through chemical functionalization. A common functionalization procedure involves the treatment of SWCNTs with nitric or nitric/sulfuric acids to introduce carboxylic acid groups at the tube ends and defect sites on the tubes. ${ }^{17,18}$ However, depending on the reaction conditions, this treatment can cut and shorten the tubes.

A recent report on the incorporation of multi-walled carbon nanotubes (MWCNTs) in a polyimide based on 3,3',4,4'-benzophenone tetracarboxylic acid dianhydride and 4,4'-oxydianiline investigated the effect of nanotube functionalization upon nanocomposite properties. ${ }^{19}$ Unmodified MWCNTs were observed to improve the surface resistance and volume resistivity of the nanocomposite by three orders of magnitude compared to functionalized (carboxylic acid and amine) MWCNTs. As expected, the length and diameter of the MWCNTs were shorter than the pristine tubes due to the acid treatment used 
for functionalization. However, sufficient information on the average aspect ratios for these materials was not provided.

The work herein describes the preparation and characterization of nanocomposites from SWCNTs, prepared by the EA method, and a low color polyimide, LaRCTM CP2. The SWCNTs were unmodified (EA-SWCNTs) and carboxylic acid functionalized (NAT-SWCNTs) materials. By atomic force microscopic analysis both SWCNT materials exhibited comparable aspect ratios, thus permitting a direct comparison of matrix effects and nanotube functionality with respect to nanocomposite properties. The first part of this work involved the incorporation of the two SWCNT types into a premade solution of an alkoxysilane terminated amide acid oligomer of LaRCTM CP2. This mixture was subsequently thermally converted to the corresponding imide/SWCNT nanocomposite. Alkoxysilanes are known to aid in the adhesion of organic materials to inorganic substrates through the formation of an oxane bond. This bond is generated from the thermal condensation of silanol groups present on the organic substrate, typically under acidic or basic hydrolysis conditions, with functionalities (e.g. hydroxyl or carboxylic) present on the inorganic component. In this work the alkoxysilane endgroups of the LaRCTM CP2 amide acid oligomer could react with the carboxylic acid moieties present on the NAT-SWCNTs and form a covalent bond. ${ }^{8}$ This chemical reaction would not be expected with the pristine EA-SWCNTs since no reactive sites are present. For both SWCNT types, noncovalent interactions (e.g. van der Waals and $\pi$ $\pi$ stacking) with the matrix would be possible.

As a comparison with the nanocomposites prepared from the alkoxysilane terminated amide acid oligomer and NAT-SWCNTs described above, LaRCTM CP2/carboxylic acid functionalized EASWCNTs (heretofore referred to as NAT-SWCNTs) were prepared via the in-situ synthetic method. ${ }^{20}$ Covalent bond formation between the carboxylic groups of the EA-SWCNTs and the amine functionality of the 1,3-bis(3-aminophenoxy) benzene monomer in the form of an amide linkage has been proposed. ${ }^{20}$ Good SWCNT dispersion was achieved in the nanocomposite by this method. However to attain the electrical resistivity necessary for ESD, a high SWCNT loading level was required. This in turn caused a significant reduction in the optical properties $(\% \mathrm{~T}<46 \%)$ at $500 \mathrm{~nm}^{19}$

Due to the inherent solubility of LaRC ${ }^{\text {TM }}$ CP2 in the imide form ${ }^{6}$, direct addition of the NATSWCNTs to the matrix was possible. Therefore the second aspect of this work was to assess the effect of covalent bond formation between the carboxylic acid groups present on the NAT-SWCNTs and the polymer matrix (in-situ and alkoxysilane endcap oligomer approaches vs. LaRCTM CP2 imide) upon nanocomposite properties. The former two approaches would lead to covalent bond formation and noncovalent interactions (e.g. van der Waals and $\pi-\pi$ stacking) with the matrix. The latter method would possess only noncovalent interactions with the matrix.

\section{EXPERIMENTAL}

\subsection{Starting Materials}

The following chemicals were obtained from the indicated sources and used without further purification: aminophenyltrimethoxysilane (APTS, Gelest Inc., 90\% meta, 10\% para), 1,3-bis(3aminophenoxy)benzene [APB, Mitsui Chemicals America, Inc., melting point (m.p.) 107-108.5 ${ }^{\circ} \mathrm{C}$, and N,N-dimethylacetamide (DMAc, Aldrich). 4,4'-Hexafluoroisopropylidene diphthalic anhydride (6FDA, Hoechst Celanese Inc., m.p. 241-243 ${ }^{\circ} \mathrm{C}$ ) was sublimed prior to use. All other chemicals were 
used as-received without further purification. LaRC ${ }^{\mathrm{TM}} \mathrm{CP} 2$ polyimide powder was obtained from SRS Technologies, Inc. ${ }^{6}$ SWCNTs, synthesized by the electric arc discharge method (EA-SWCNTs) using nickel and yttrium as a catalyst, ${ }^{21,22}$ were obtained from Carbon Solutions, Inc.. The EA-SWCNTs were purified by air oxidation followed by treatment in aqueous $\mathrm{HCl}$ to remove metal residue. The EASWCNTs were subsequently treated with nitric acid to generate carboxylic acid functionality and are defined as NAT-SWCNTs. ${ }^{17,18}$

\subsection{Synthesis of Alkoxysilane Terminated Amide Acid Oligomer of LaRC ${ }^{\text {TM }}$ CP2}

An alkoxysilane terminated amide acid (ASTAA) of LaRC ${ }^{\text {TM }}$ CP-2 was prepared by the reaction of 6FDA with APB and end-capped with APTS at a $2.5 \%$ stoichiometric offset. ${ }^{8}$ A representative procedure is described. To a $100 \mathrm{~mL}$ round bottom flask equipped with a nitrogen inlet, mechanical stirrer, and drying tube filled with calcium sulfate was charged APB $(9.0703 \mathrm{~g}, 0.0310 \mathrm{~mol})$ and APTS $(0.3394 \mathrm{~g}$, $0.0016 \mathrm{~mol})$. These were dissolved in DMAc $(10 \mathrm{~mL})$ at room temperature under nitrogen. The flask was subsequently immersed in a water bath to dissipate the heat of reaction due to the dianhydride addition. 6-FDA (14.1368 g, $0.0318 \mathrm{~mol})$ was added in one portion as a slurry in DMAc $(17 \mathrm{~mL})$ and rinsed in with $20 \mathrm{~mL}$ of DMAc to afford a solution with a solids content of $\sim 35 \%$. The reaction mixture was stirred for $\sim 24 \mathrm{~h}$ at room temperature under nitrogen. The inherent viscosity $\left(\eta_{\text {inh }}\right)$ was $0.66 \mathrm{dL} / \mathrm{g}$ in DMAc at $25^{\circ} \mathrm{C}$. The solution was used as-is or SWCNTs were added as described in Sections 2.3 and 2.4 .

\subsection{Blending of SWCNTs and ASTAA}

Nanocomposite solutions were prepared by the addition of a sonicated mixture of EA-SWCNTs or NAT-SWCNTs in DMAc to a pre-weighed polymer solution while stirring. The loadings of SWCNTs were determined in weight $(\mathrm{wt}) \%$ based on the mass of polymer used. A representative procedure is described. To a $100 \mathrm{~mL}$ round bottom flask equipped with nitrogen inlet, mechanical stirrer, and drying tube filled with calcium sulfate was charged $5.75 \mathrm{~g}$ of an ASTAA solution ( $\sim 35 \%$ solids). In a separate tared vial, EA-SWCNTs $(0.0062 \mathrm{~g})$ were placed in $3 \mathrm{~mL}$ of DMAc and the mixture sonicated for $\sim 2.5 \mathrm{~h}$ in a Degussa-Ney ULTRAsonik $57 \mathrm{X}$ Cleaner operated at $\sim 50 \%$ power and degas levels. The temperature of the water bath was initially ambient and $\sim 40^{\circ} \mathrm{C}$ at the conclusion of sonication. The suspended tubes were subsequently added to the stirred mixture of ASTAA at room temperature and rinsed in with $1.2 \mathrm{~mL}$ of DMAc to afford a solids content of $\sim 20 \%$. The SWCNT loading was $0.3 \mathrm{wt} \%$. The mixture was stirred under a nitrogen atmosphere at room temperature for $\sim 16 \mathrm{~h}$ prior to film casting.

\subsection{Blending of NAT-SWCNTs with LaRCTM CP2}

Nanocomposite solutions were prepared by the addition of a sonicated mixture of NAT-SWCNTs in DMAc to a known quantity of LaRCTM CP2 dissolved in DMAc. A representative procedure is described. To a $100 \mathrm{~mL}$ round bottom flask was charged $3.03 \mathrm{~g}$ of polyimide powder. The flask was then fitted with a nitrogen inlet, mechanical stirrer, and drying tube filled with calcium sulfate and charged with $6 \mathrm{~mL}$ of DMAc to afford a $\sim 35 \%$ solids content. In a separate tared vial, NAT-SWCNTs $(0.0031 \mathrm{~g})$ were placed in $3 \mathrm{~mL}$ of DMAc and the mixture sonicated for $\sim 2.5 \mathrm{~h}$ as described in Section 2.3. The suspended tubes were subsequently added to the stirred mixture and rinsed in with $4 \mathrm{~mL}$ of 
DMAc to afford a solids content of $\sim 20 \%$. The NAT-SWCNT loading was $0.1 \mathrm{wt} \%$. The mixture was stirred under a nitrogen atmosphere at room temperature for $\sim 16 \mathrm{~h}$ prior to film casting.

\subsection{Films}

DMAc solutions of the nanocomposites were doctored onto plate glass and dried to tack free forms in a low humidity chamber at ambient temperature. The films were cured on the glass plate in a forced air oven at 100,200 , and $300^{\circ} \mathrm{C}$ for $1 \mathrm{~h}$ each. The films were subsequently removed from the glass plate and characterized. Room temperature thin-film tensile properties were determined according to ASTM D882 using four specimens.

\subsection{Characterization}

Inherent viscosities were obtained on $0.5 \%(\mathrm{w} / \mathrm{v})$ amide acid solutions in DMAc at $25^{\circ} \mathrm{C}$. Differential scanning calorimetry (DSC) was conducted on a Shimadzu DSC-50 thermal analyzer. Melting point ranges (tangent of onset to melt and the endothermic peak) were determined at a heating rate of $10^{\circ} \mathrm{C} / \mathrm{min}$. Glass transition temperatures $\left(\mathrm{T}_{\mathrm{gs}}\right)$ were determined at a heating rate of $20^{\circ} \mathrm{C} / \mathrm{min}$ and taken as the inflection point of the $\Delta \mathrm{H}$ vs. temperature curve. FTIR was obtained on a Nicolet Magna-IR 560 ESP spectrometer on $\mathrm{KBr}$ pellets. Raman spectroscopy was performed using a Thermo Nicolet Almega Dispersive Raman spectrometer equipped with a $785 \mathrm{~nm}$ laser. UV/VIS spectra were obtained on thin films using a Perkin-Elmer Lambda 900 UV/VIS/NIR and Shimadzu UV3100 UVVIS/NIR spectrometers. Near-IR (NIR) spectra were obtained on dimethylformamide solutions at a SWCNT concentration of $0.01 \mathrm{mg} / \mathrm{mL}$ on a Varian Cary 500 spectrophotometer. Atomic force microscopy (AFM) images were obtained on a Digital Instruments Nanoscope IIIA operating in the tapping mode. Solar absorptivities $(\alpha)$ were measured on an AZ Technology Model LPSR-300 spectroreflectometer with measurements taken from 250 to $2800 \mathrm{~nm}$ with a vapor deposited aluminum on Kapton ${ }^{\circledR}$ film (1st surface mirror) as a reflective reference for air mass 0 per ASTM E903. An AZ Technology Temp 2000A infrared reflectometer was used to measure thermal emissivity ( $\varepsilon$ ). High-resolution scanning electron microscopy (HRSEM) images were obtained on Hitachi S-4700 and S-5200 field emission scanning electron microscopy systems. Surface resistance was determined per EOS/ESD Standard S11.11-1993 using a Prostat ${ }^{\circledR}$ PRS-801 Resistance System operating at 10-100 volts and reported as an

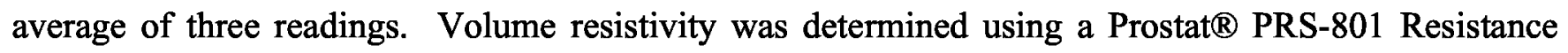
System with a PRF-911 Concentric Ring Fixture operating at 10-100 volts according to ASTM D-257.

\section{RESULTS AND DISCUSSION}

\subsection{SWCNTs}

The SWCNTs utilized in this work were prepared by the electric arc discharge (EA) method. The asprepared EA-SWCNTs were purified by air oxidation followed by treatment in $\mathrm{HCl}$ to remove residual metal catalyst Typically this purification procedure provides SWCNTs with little or no chemical functionality. The relative carbonaceous purity of SWCNTs was estimated from the spectral region of the second interband transition for semiconducting SWCNTs $\left(S_{22}\right.$, spectral cutoff $\left.7750-11750 \mathrm{~cm}^{-1}\right)$ in the NIR spectra against an in-house reference material R2. ${ }^{2324}$ Based on this method the relative carbonaceous purity of EA-SWCNTs was $\sim 80 \%$ (Figure 1a). The Raman spectrum showed the expected 


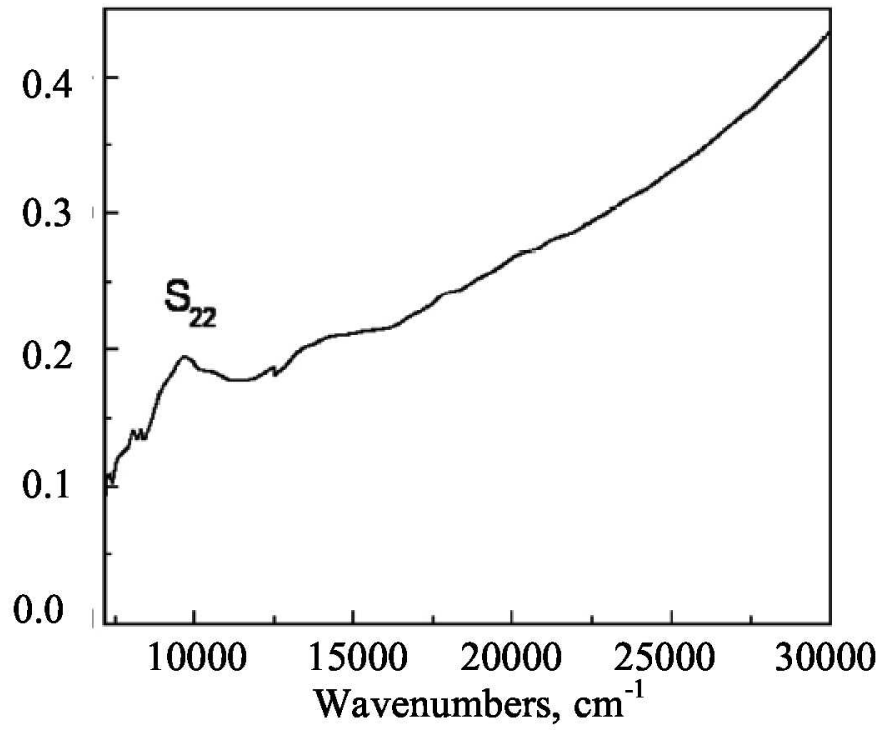

(a)

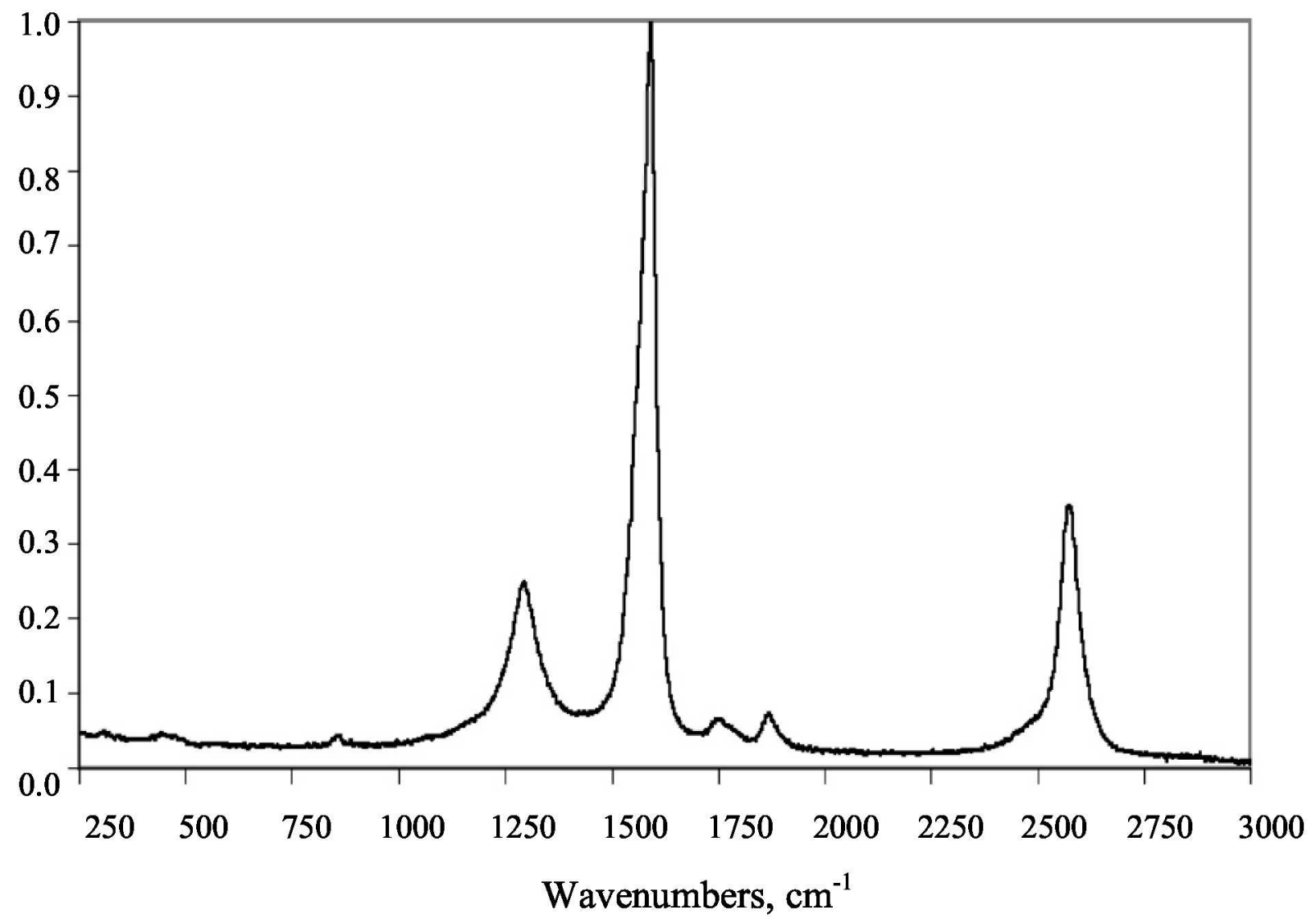

(b)

Figure 1. EA-SWCNT (a) solution phase NIR and (b) Raman spectrum. 


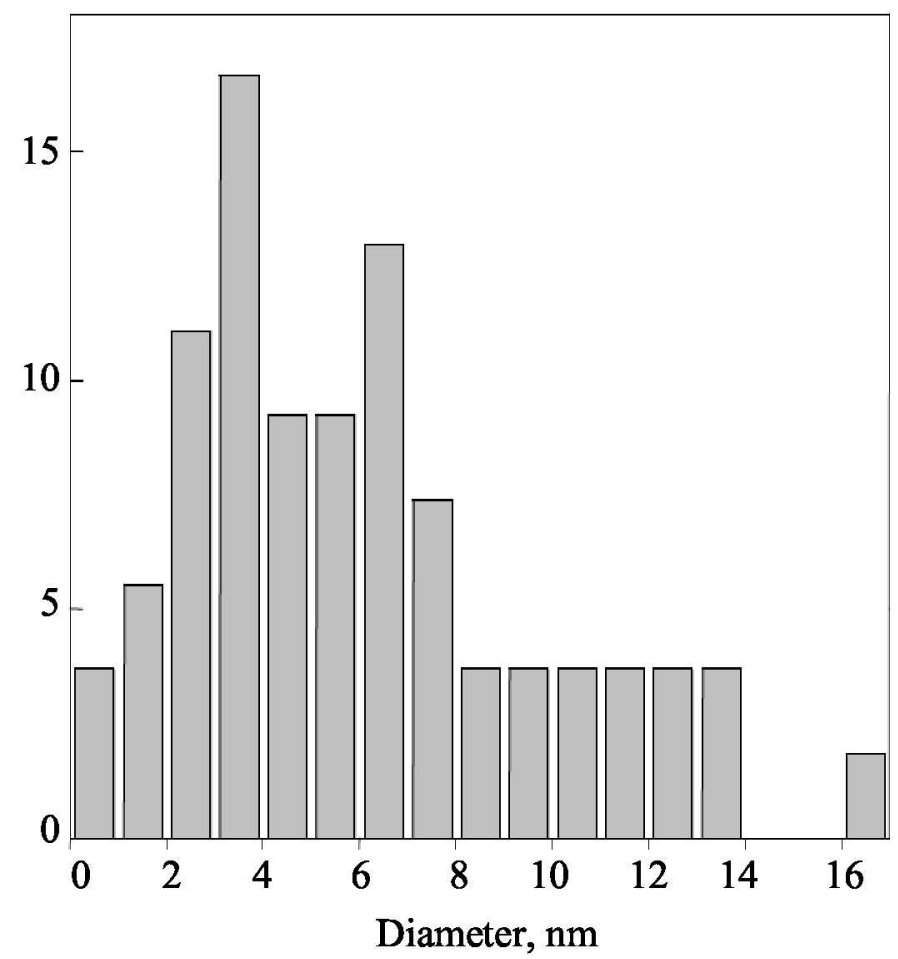

(a)

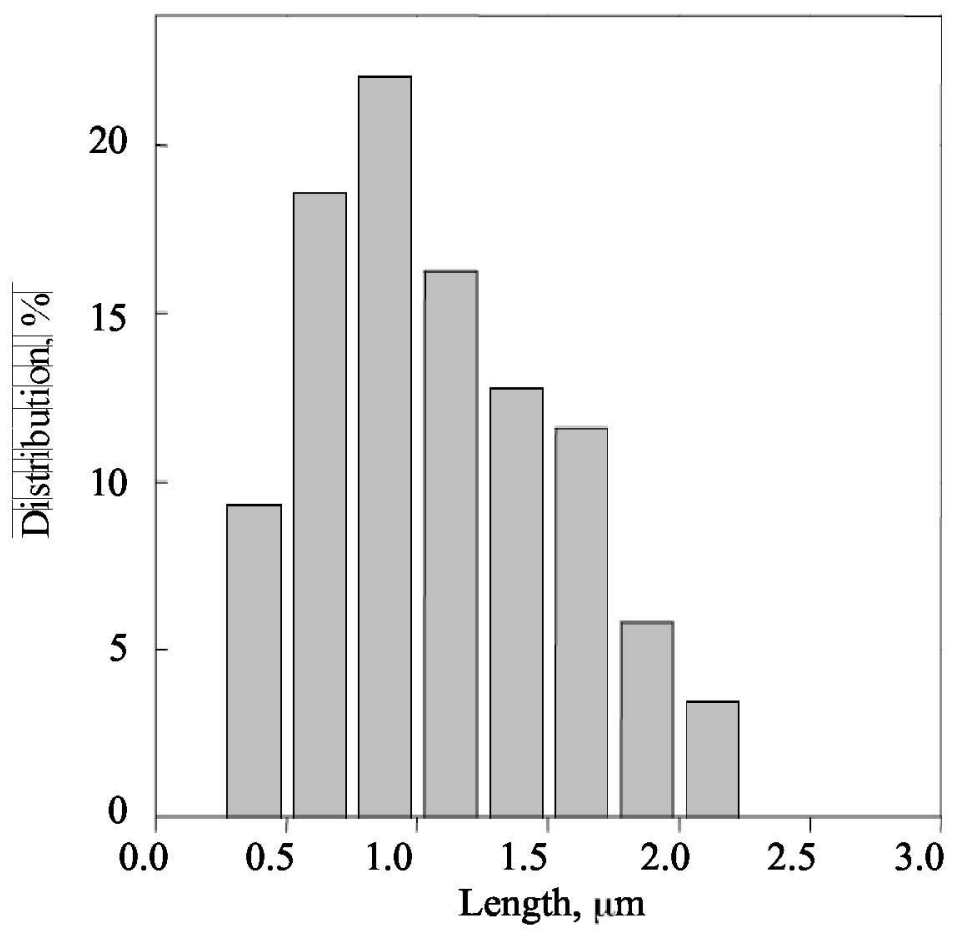

(b)

Figure 2. EA-SWCNT distributions by (a) diameter and (b) length. 


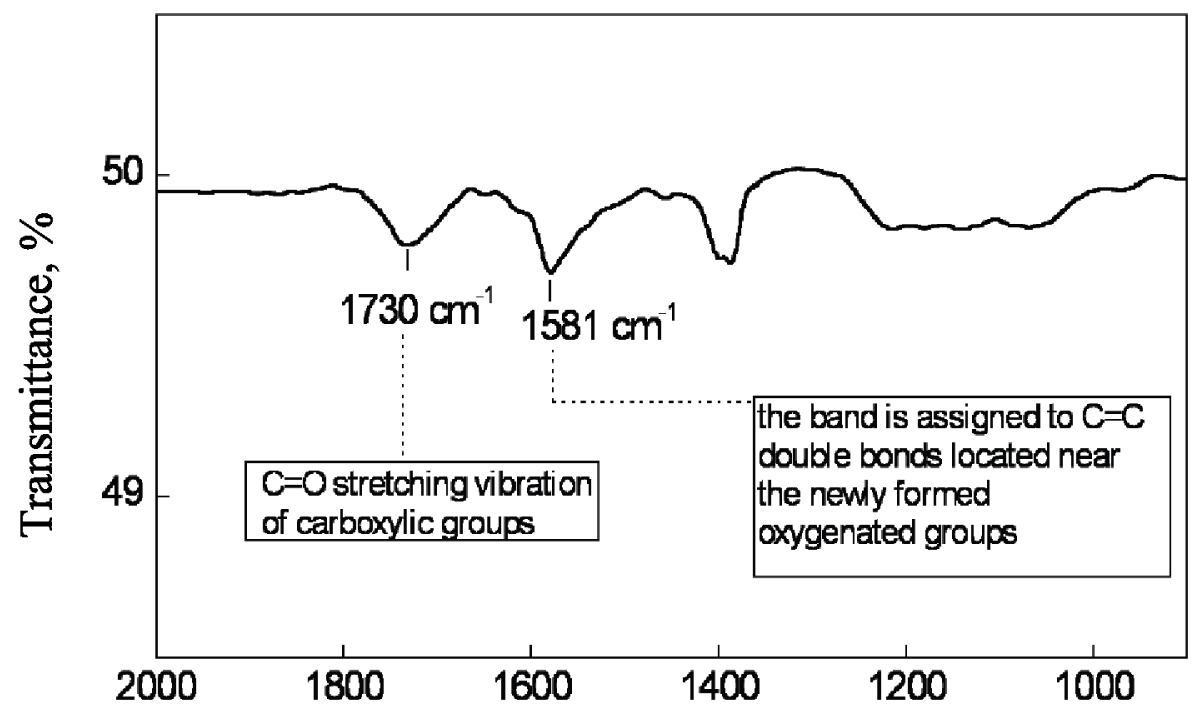

Wavenumbers, $\mathrm{cm}^{-1}$

Figure 3. FTIR spectrum of NAT-SWCNTs

absorption peaks at $\sim 1300$ (D band) and $1600 \mathrm{~cm}^{-1}$ ( $\mathrm{G}$ band) associated with SWCNTs (Figure $1 \mathrm{~b}$ ). By AFM, the EA-SWCNTs have approximate diameters and length of 4-6 nm and $1 \mu \mathrm{m}$, respectively (Figure 2). The aspect ratio based on these dimensions ranged from 167 to 250 .

A second batch of EA-SWCNTs was treated with nitric acid using an optimized procedure and afforded functionalized SWCNTs (NAT-SWCNTs) ${ }^{23,25}$ with carboxylic acids on the open ends and defect sites. ${ }^{1724}$ The formation of these groups was confirmed by the appearance of the carbonylstretching band at $1730 \mathrm{~cm}^{-1}$ in the FTIR spectrum (Figure 3). The relative carbonaceous purity determined from the solution phase NIR spectrum was $95 \%$ (Figure 4a). The Raman spectra (Figure 4b) showed a greater percentage of $\mathrm{sp}^{3}$-hybridized carbon (D band) compared to the pristine EA-SWCNTs (Figure 1b). By AFM, the NAT-SWCNTs consisted of bundles with approximate diameters and length of 4-6 $\mathrm{nm}$ and $\sim 1.0 \mu \mathrm{m}$, respectively (Figure 5). The NAT-SWCNTs exhibited a comparable aspect ratio range to that of the first batch of EA-SWCNTs described above indicating that the nitric acid treatment did not cut the tubes.

\subsection{Nanocomposites Prepared from Alkoxysilane Terminated LaRCTM CP2 Amide Acids}

The approach taken to homogeneously disperse the SWCNTs involved the use of oligomeric materials terminated with reactive endgroups (i.e., trimethoxysilane). The oligomer was based on the LaRC $^{\text {TM }}$ CP2 backbone prepared at a stoichiometric offset of $2.5 \%$ which corresponds to a calculated $\overline{\mathrm{M}}_{\mathrm{n}}$ of $\sim 27,700 \mathrm{~g} / \mathrm{mol}$ (Scheme 1 ). ${ }^{8}$ Nanocomposite solutions were prepared by the addition of a sonicated suspension of the appropriate SWCNT type in DMAc to a stirred solution of this premade oligomer. Solutions were stirred for $\sim 16 \mathrm{~h}$ at ambient temperature prior to film casting. Once dried to atack free state, the films were cured to $300^{\circ} \mathrm{C}$ in flowing air to effect imidization and 


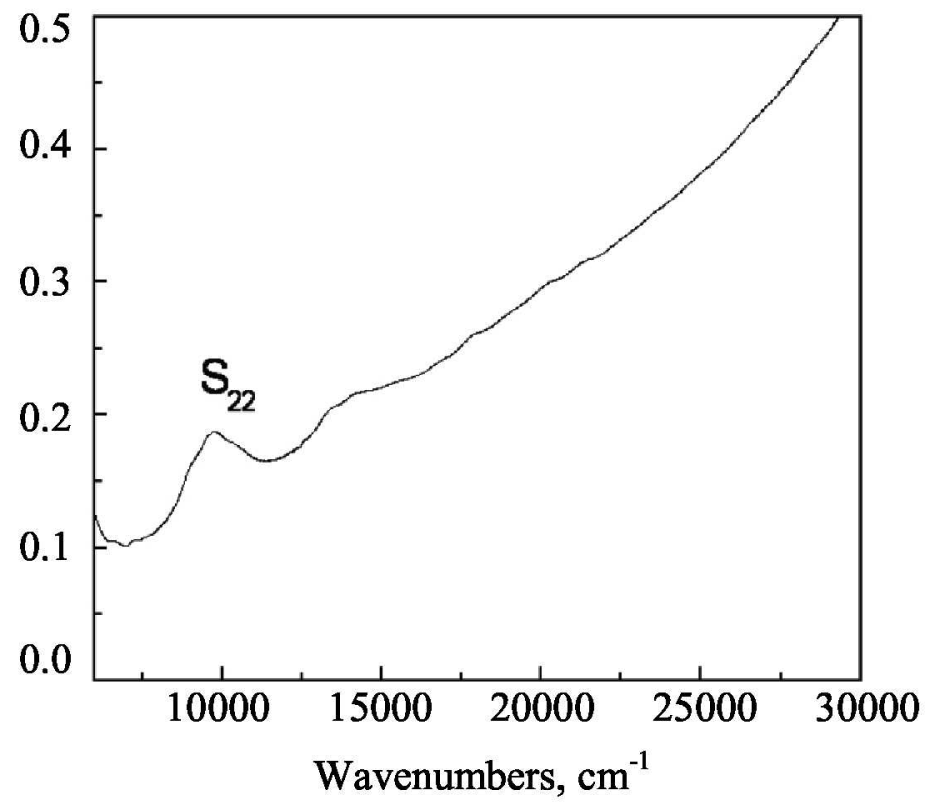

(a)



(b)

Figure 4. NAT-SWCNT (a) solution phase NIR and (b) Raman spectrum. 


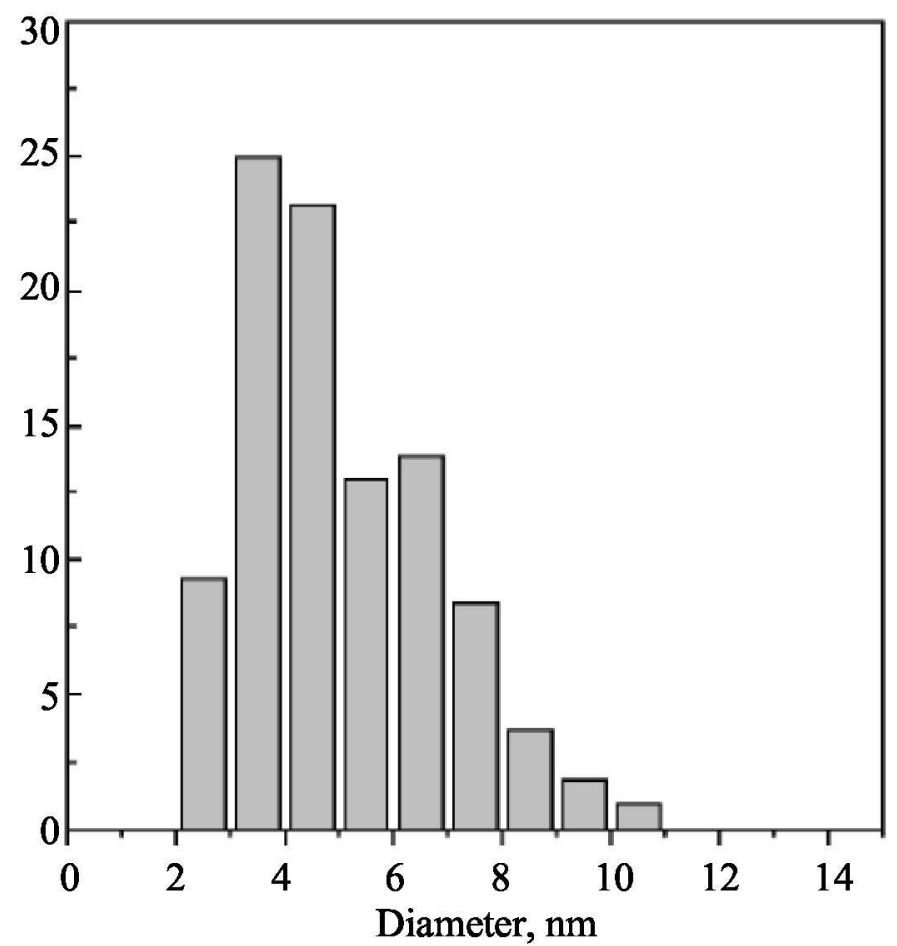

(a)

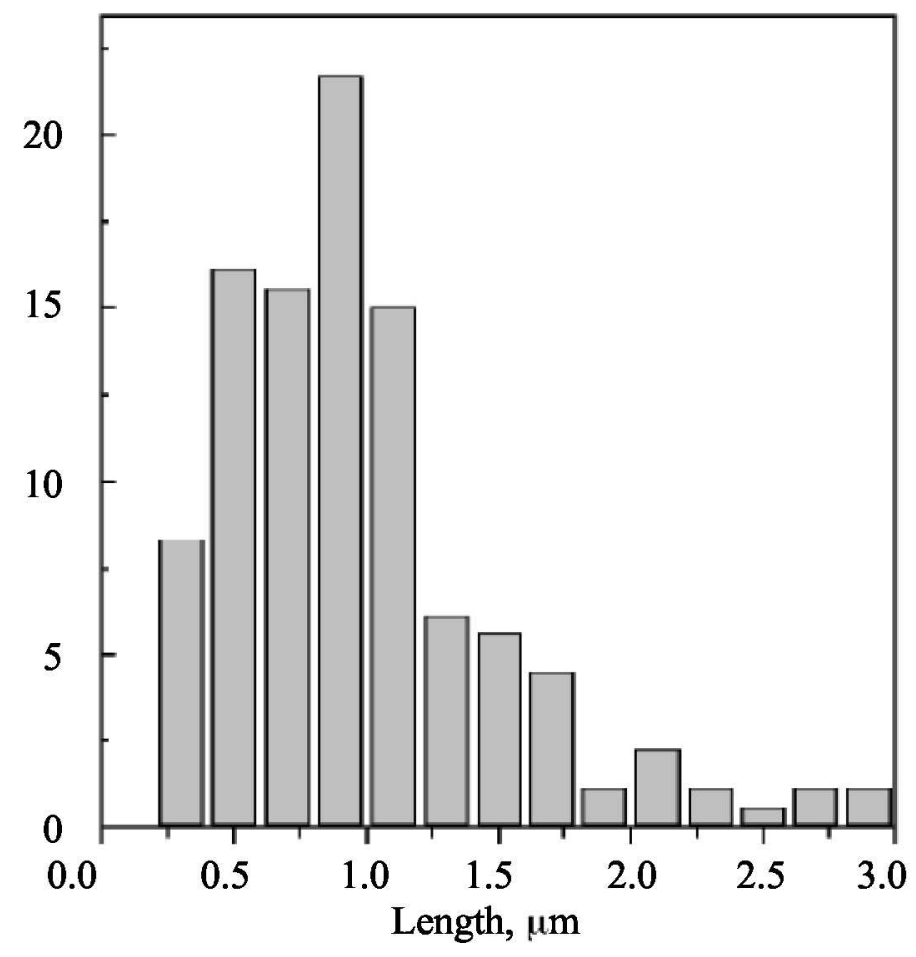

(b)

Figure 5. NAT-SWCNT distributions by (a) diameter and (b) length. 


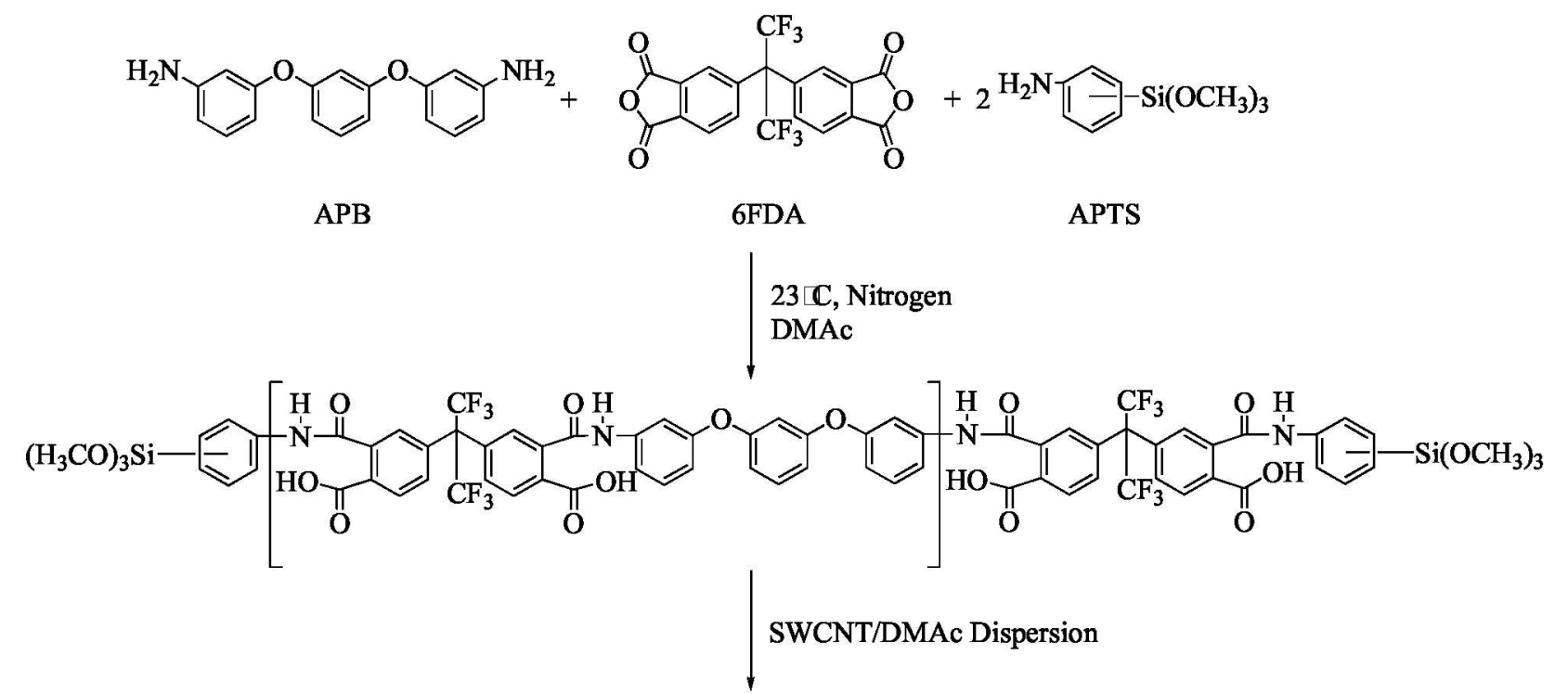

Alkoxysilane Terminated Amide Acid/SWCNT Mixture

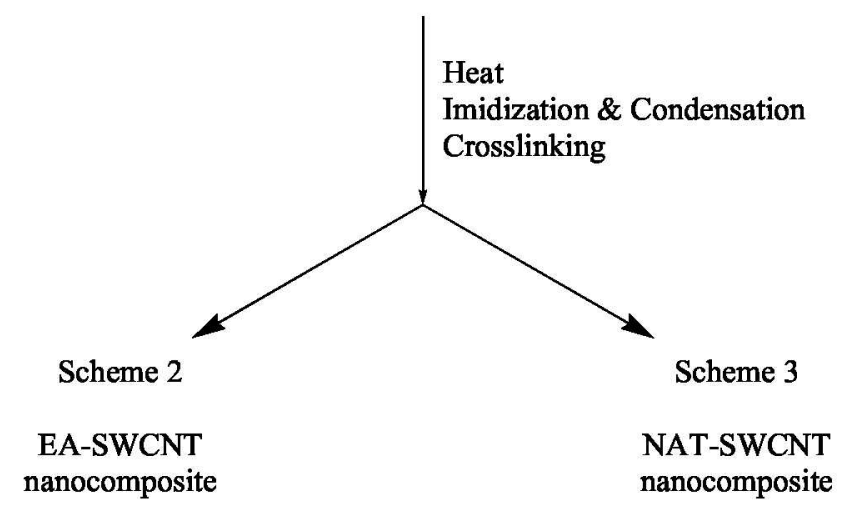

Scheme 1. Synthesis of SWCNT nanocomposites from Alkoxysilane Terminated Amide Acids.

condensation of the silanol groups generated from the alkoxysilane endgroups. In this case, an acid catalyst was not required for the hydrolysis and condensation of the alkoxysilane endgroups due to the acidic nature of the amide acid.

Scheme 2 depicts the EA-SWCNTs dispersed throughout this matrix. Due to the lack of any chemical functionality on the EA-SWCNTs interactions between the two materials is electronic (van der

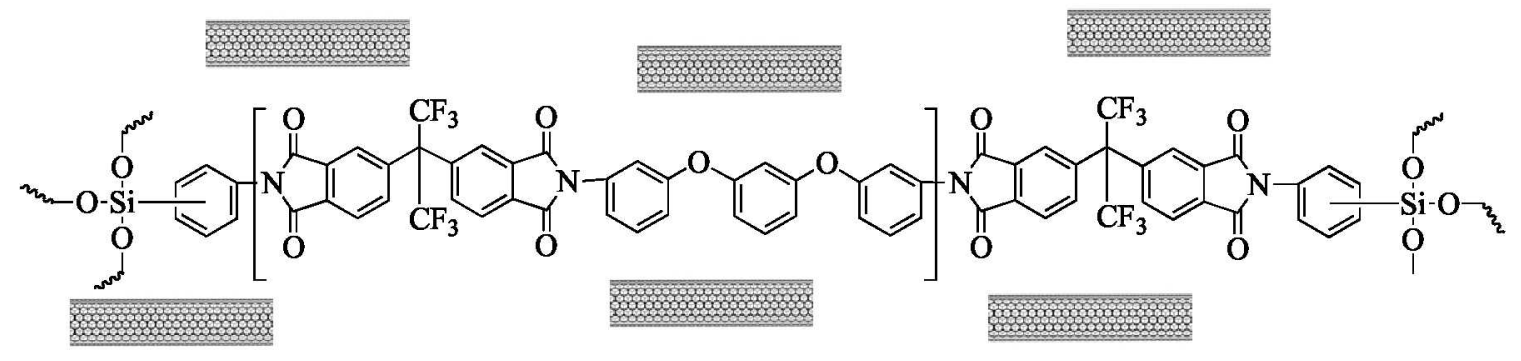

Scheme 2. EA-SWCNT nanocomposite 


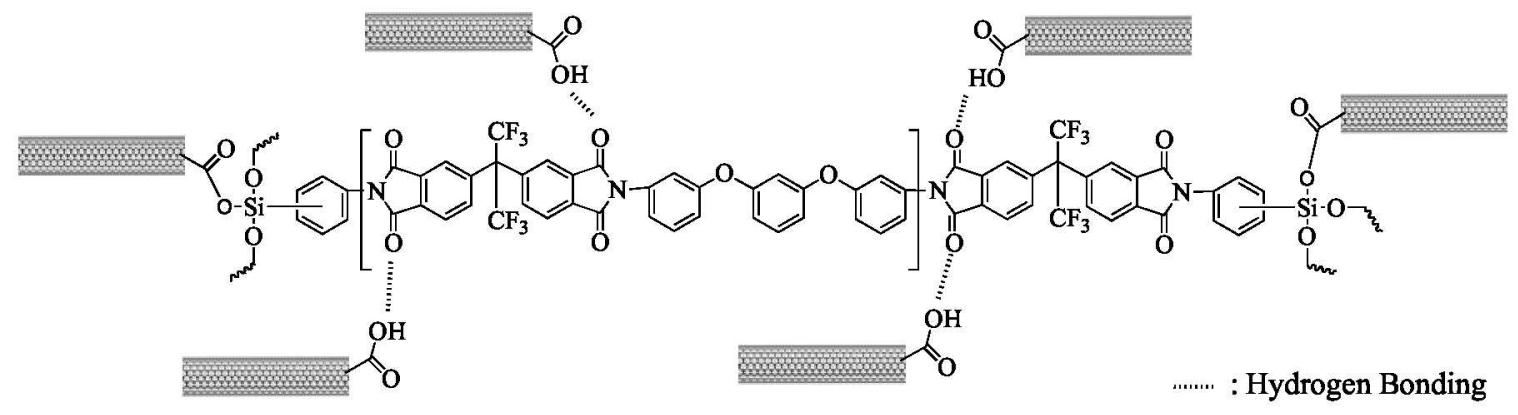

Scheme 3. NAT-SWCNT nanocomposite.

Waals and $\pi$ - $\pi$ stacking). However NAT-SWCNTs could form covalent and hydrogen bonds with this matrix as depicted in Scheme 3 in addition to the electronic interactions. Similar interactions have been described with the NAT-SWCNTs and the resultant nanocomposite with LaRC'M CP2 by the in-situ preparative approach. ${ }^{20}$

To assess dispersion, the nanocomposite films were analyzed by HRSEM. The image obtained for the $0.5 \mathrm{wt} \%$ NAT-SWCNT film showed that the SWCNTs were uniformly dispersed throughout the matrix (Figure 6). This was typical for films with inherent electrical conductivity sufficient for HRSEM analysis.

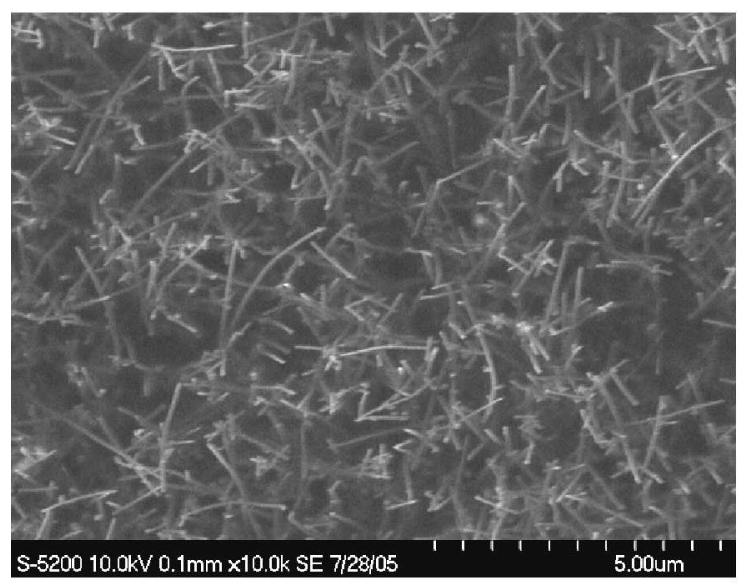

Figure 6. HRSEM image of VI containing $0.5 \mathrm{wt} \%$ loading NAT-SWCNT.

The $\mathrm{Tg}$ and room temperature thin film tensile properties were unaffected by the low loading levels of SWCNTs employed (Table 1). Similar results have been reported using HiPco SWCNTs. ${ }^{8}$

Table 1. ASTAA Nanocomposite Film Characterization.

\begin{tabular}{|c|c|c|c|c|c|c|}
\hline & SWCNT & SWCNT, & Tg, & \multicolumn{3}{|c|}{ Tensile Properties } \\
\cline { 5 - 7 } ID & Type & wt \% & ${ }^{\circ} \mathrm{C}$ & Strength, MPa & Modulus, GPa & Elong., \% \\
\hline I & none & 0 & 206 & $122 \pm 2.8$ & $3.39 \pm 0.04$ & 6 \\
\hline II & EA & 0.05 & 206 & $110 \pm 8$ & $3.07 \pm 0.15$ & 5 \\
\hline III & EA & 0.08 & 206 & $114 \pm 0.5$ & $3.07 \pm 0.09$ & 5 \\
\hline IV & NAT & 0.08 & 207 & $110 \pm 3$ & $2.95 \pm 0.05$ & 5 \\
\hline V & NAT & 0.35 & 205 & $119 \pm 0.5$ & $3.11 \pm 0.05$ & 6 \\
\hline VI & NAT & 0.5 & 205 & $114 \pm 4$ & $3.09 \pm 0.03$ & 5 \\
\hline
\end{tabular}


The optical transparency at $500 \mathrm{~nm}$ and thermo-optical properties ( $\alpha$ and $\varepsilon$ ) for the nanocomposite films are reported in Table 2. These properties are known to be dependent on film thickness and attempts were made to obtain samples of similar thickness. Film thickness ranged from 45 to $47.5 \mu \mathrm{m}$ thus allowing direct comparisons without normalization. In general, as SWCNT (EA and NAT) loading increased the $\% \mathrm{~T}$ at $500 \mathrm{~nm}$ decreased while $\alpha$ and $\varepsilon$ increased. Similar results have been reported for HiPco SWCNT nanocomposite films. ${ }^{8}$ Since films III and IV have $0.08 \mathrm{wt} \%$ of the respective SWCNT type in this matrix, a comparison of properties with regards to functionalization could be made. Film IV based on the NAT-SWCNTs exhibited a higher \%T and lower $\alpha$ compared to film III based on EASWCNTs. This was attributed to the differences in relative carbonaceous purity of the NAT-SWCNTs vs. that of the EA-SWCNTs, 95 and $80 \%$ respectively. The $\varepsilon$ was the same at the $0.08 \mathrm{wt} \%$ loading regardless of which type of SWCNT was used.

Table 2. Optical and Thermo-optical Properties of ASTAA Nanocomposite Films.

\begin{tabular}{|c|c|c|c|c|c|c|}
\hline ID & SWCNT Type & $\begin{array}{c}\text { SWCNT } \\
\text { wt \% }\end{array}$ & $\begin{array}{c}\text { Film } \\
\text { Thickness, } \mu \mathrm{m}\end{array}$ & $\begin{array}{c}\% \mathrm{~T} @ \\
500 \mathrm{~nm}\end{array}$ & $\alpha$ & $\varepsilon$ \\
\hline I & None & 0 & 47.5 & 85 & 0.06 & 0.60 \\
\hline II & EA & 0.05 & 45 & 65 & 0.23 & 0.61 \\
\hline III & EA & 0.08 & 45 & 47 & 0.34 & 0.61 \\
\hline IV & NAT & 0.08 & 45 & 58 & 0.27 & 0.60 \\
\hline V & NAT & 0.35 & 45 & 16 & 0.62 & 0.69 \\
\hline VI & NAT & 0.5 & 45 & 11 & 0.69 & 0.71 \\
\hline
\end{tabular}

A similar trend for \% $\mathrm{T}$ at $500 \mathrm{~nm}$ was observed for nanocomposites prepared from LaRCTM CP2 and NAT-SWCNTs by the in-situ approach. ${ }^{20}$ The $0.08 \mathrm{wt} \%$ loading of NAT-SWCNTs in reference 20 exhibited a \%T at $500 \mathrm{~nm}$ of 73 and 64 for unbundled and bundled NAT-SWCNTs, respectively. The $\% \mathrm{~T}$ of film IV with a similar loading of NAT-SWCNTs was comparable to that of the bundled tubes; however, film IV was thicker $(45 \mu \mathrm{m})$ than that in reference $20(40 \mu \mathrm{m})$.

Electrical properties were determined as surface resistance and volume resistivity (Table 3). The nanocomposite films showed a decrease in the surface resistance and volume resistivity with the incorporation of SWCNTs as expected. However the amount of this decrease depended on the SWCNT type (EA or NAT) used in this matrix. The surface resistance and volume resistivity of II and III decreased five orders of magnitude between the 0.05 and $0.08 \mathrm{wt} \%$ loading of EA-SWCNTs, respectively, implying that the percolation threshold fell within these bounds. The surface resistance of III was within the level needed for the prevention of ESC accumulation. Similar results were obtained

Table 3. Thin Film Electrical Characterization of ASTAA Nanocomposite Films.

\begin{tabular}{|c|c|c|c|c|}
\hline ID & SWCNT Type & $\begin{array}{c}\text { SWCNT } \\
\text { wt } \%\end{array}$ & $\begin{array}{c}\text { Surface } \\
\text { Resistance, } \Omega / \mathrm{sq}\end{array}$ & $\begin{array}{c}\text { Volume } \\
\text { Resistivity, } \Omega \mathrm{cm}\end{array}$ \\
\hline I & None & 0 & $1.4 \times 10^{14}$ & Not Determined \\
\hline II & EA & 0.05 & $8.1 \times 10^{11}$ & $6.1 \times 10^{14}$ \\
\hline III & EA & 0.08 & $8.0 \times 10^{6}$ & $2.6 \times 10^{9}$ \\
\hline IV & NAT & 0.08 & $7.4 \times 10^{11}$ & $6.0 \times 10^{14}$ \\
\hline V & NAT & 0.35 & $9.8 \times 10^{10}$ & $2.3 \times 10^{12}$ \\
\hline VI & NAT & 0.5 & $8.2 \times 10^{9}$ & $1.2 \times 10^{11}$ \\
\hline
\end{tabular}


using HiPco SWCNTs, but this occurred between a 0.035 and $0.05 \mathrm{wt} \%$ loading. ${ }^{8}$ The increased loading needed to attain the percolation threshold using EA-SWCNTs may be due to differences in the average aspect ratio and relative carbonaceous purity compared to HiPco SWCNTs. The NAT-SWCNT containing films (IV-VI) did not show this sharp drop in surface resistance and volume resistivity, even when the SWCNT loading was much higher than that of the EA-SWCNTs. For example, even at nearly an order of magnitude higher loading level, the NAT-SWCNT containing films exhibited significantly higher surface resistance and volume resistivity than the EA-SWCNT containing films. The surface resistance of VI was within the level needed for the prevention of ESC accumulation, but was three orders of magnitude higher than III. For comparison, the bundled and unbundled 0.08 wt $\%$ NATSWCNT/LaRCTM CP2 nanocomposite prepared via the in-situ approach described in reference 20 provided a comparable volume resistivity $\left(1.2 \times 10^{14}\right.$ and $2.3 \times 10^{13} \Omega \mathrm{cm}$, respectively) to that of film IV.

\subsection{Nanocomposites Prepared from LaRC ${ }^{\text {TM }}$ CP2}

Since the EA and NAT SWCNTs have comparable average aspect ratios, the difference in the electrical properties of the above nanocomposite series may be attributed to covalent bond formation between the alkoxysilane endgroups of the matrix with the carboxylic acid functionality of the NATSWCNTs (Scheme 3). To determine if this difference in electrical properties was indeed due to the matrix, films were prepared from the NAT-SWCNTs and pre-imidized LaRC ${ }^{\text {TM }}$ CP2 that had no reactive endgroups. For information, LaRCTM CP2 is soluble in common organic solvents as the imide. ${ }^{6}$ The use of this matrix eliminated the possibility of any chemical reaction between the polymer and the carboxylic acid groups on NAT-SWCNTs resulting in primarily electronic (van der Waals and $\pi-\pi$ stacking) interactions between the two species. However hydrogen bonding effects between the two materials was still a possibility (Scheme 4) as was proposed between MWCNTs bearing carboxylic acid groups and the carbonyl groups on the polyimide from 3,3',4,4'-benzophenone tetracarboxlyic acid dianhydride and 4,4'-oxydianiline. ${ }^{19}$

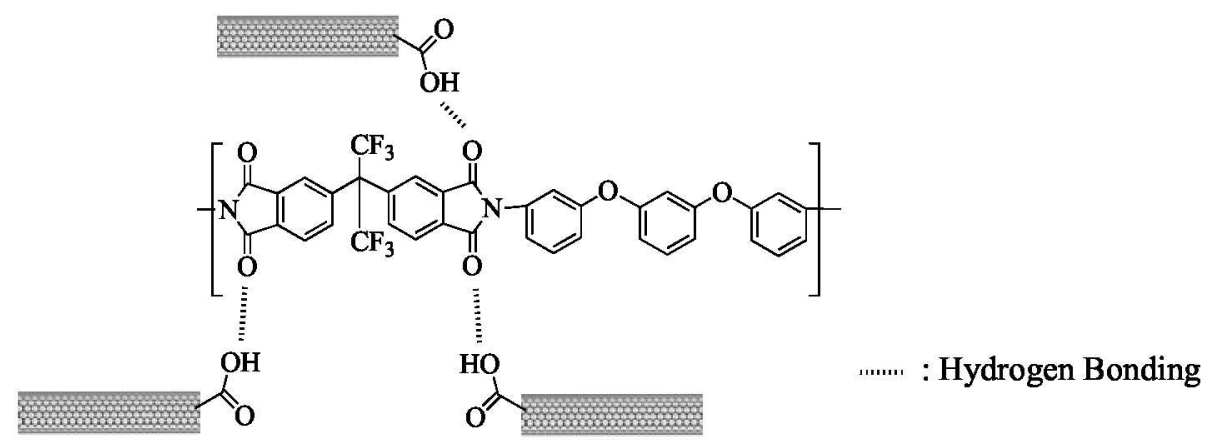

Scheme 4. NAT-SWCNT/ LaRCTM CP2 nanocomposite.

The HRSEM image of XII containing $0.35 \mathrm{wt}^{\circ}$ NAT-SWCNTs/LaRC ${ }^{\mathrm{TM}}$ CP2 showed that the SWCNTs were uniformly dispersed in the polymer (Figure 7).

The electrical data in Table 4 shows that the 0.08 (film X) wt\% loading of NAT-SWCNTs in LaRCTM CP2 exhibited 2-4 orders of magnitude lower values than that obtained for NAT-SWCNTs in the ASTAA based material at a $0.08 \mathrm{wt} \%$ loading (Table 3, IV). Additionally, the volume resistivity for film 


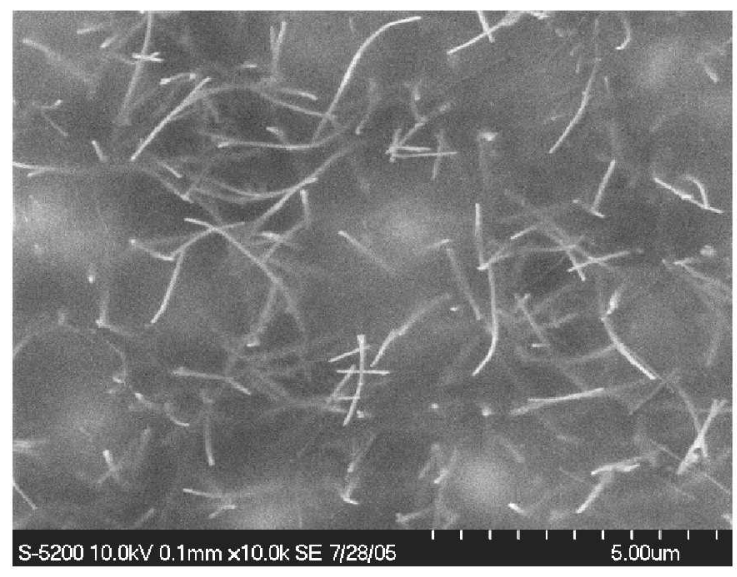

Figure 7. HRSEM image of $0.35 \mathrm{wt} \%$ NAT-SWCNTs/LaRC ${ }^{\text {TM }}$ CP2 nanocomposite film.

$\mathrm{X}$ was 3 and 4 orders of magnitude lower than the unbundled and bundled tubes: $2.3 \times 10^{13}$ and $1.2 \times$ $10^{14} \Omega \mathrm{cm}$, respectively, at a comparable loading. ${ }^{20}$ This implies that the covalent reaction between NAT-SWCNTs and the matrix (alkoxysilane in this work and diamine monomer in reference 20) influenced the electrical properties of the resultant nanocomposite. The electrical properties for $\mathrm{X}(0.08$ wt $\%$ NAT-SWCNTs) though were still 1-3 orders of magnitude larger than that obtained for film III in the ASTAA matrix with a $0.08 \mathrm{wt} \%$ loading of EA-SWCNTs. This difference may be due to hydrogen bonding effects between the carboxylic acid functionalities of the NAT-SWCNTs and the imide carbonyls of the matrix as well as other NAT-SWCNTs. It is known that functionalization leads to a decrease in nanotube properties, therefore the results are not unexpected. Further conclusions can not be made at this time with regards to matrix effects due to an insufficient quantity of this batch of EASWCNTs to be mixed in the LaRCTM CP2 matrix. The surface resistance of VIII $(0.03 \mathrm{wt} \%)$ was at the high end of the range necessary for ESC mitigation while XII $(0.35 \mathrm{wt} \%)$ was at the low end.

The optical and thermo-optical properties of NAT-SWCNTs in LaRCTM CP2 are presented in Table 5. The film thicknesses were similar to those reported in Table 2 so a direct comparison could be made. The $\% \mathrm{~T}$ at $500 \mathrm{~nm}$ and $\alpha$ were essentially the same for base polymer films I and VII implying that the endgroups had minimal effect. With increasing SWCNT wt\% loading, the \%T at $500 \mathrm{~nm}$ decreased and $\alpha$ and $\varepsilon$ increased as expected. These properties for the $0.08 \mathrm{wt} \%$ loading of NAT-SWCNTs were comparable regardless of the matrix used in this study. For comparison, the \% $\mathrm{T}$ at $500 \mathrm{~nm}$ for $\mathrm{X}$ was comparable to that of the bundled tubes (64\%) of the same wt\% loading in reference 20 even though $\mathrm{X}$ was thicker (45 for X vs. $40 \mu \mathrm{m}$ in reference 20 ).

Table 4. Thin Film Electrical Properties of LaRCTM CP2 Nanocomposite Films.

\begin{tabular}{|c|c|c|c|}
\hline ID & $\begin{array}{c}\text { NAT-SWCNT, } \\
\text { wt } \%\end{array}$ & $\begin{array}{c}\text { Surface } \\
\text { Resistance, } \Omega / \mathrm{sq}\end{array}$ & $\begin{array}{c}\text { Volume } \\
\text { Resistivity, } \Omega \mathrm{cm}\end{array}$ \\
\hline VII & 0 & $>10^{12}$ & $4.2 \times 10^{14}$ \\
\hline VIII & 0.03 & $4.1 \times 10^{10}$ & $6.9 \times 10^{12}$ \\
\hline IX & 0.05 & $8.8 \times 10^{9}$ & $2.9 \times 10^{11}$ \\
\hline X & 0.08 & $4.2 \times 10^{9}$ & $8.5 \times 10^{10}$ \\
\hline XI & 0.1 & $1.3 \times 10^{9}$ & $2.4 \times 10^{10}$ \\
\hline XII & 0.35 & $4.7 \times 10^{7}$ & $1.7 \times 10^{9}$ \\
\hline
\end{tabular}


Table 5. Optical and Thermo-optical Properties of LaRCTM CP2 Nanocomposite Films.

\begin{tabular}{|c|c|c|c|c|c|}
\hline ID & NAT-SWCNT, wt \% & Thickness, $\mu \mathrm{m}$ & $\% \mathrm{~T} @ 500 \mathrm{~nm}$ & $\alpha$ & $\varepsilon$ \\
\hline VII & 0 & 45 & 85 & 0.07 & 0.57 \\
\hline VIII & 0.03 & 45 & 71 & 0.16 & 0.60 \\
\hline IX & 0.05 & 45 & 67 & 0.19 & 0.60 \\
\hline X & 0.08 & 45 & 62 & 0.24 & 0.61 \\
\hline XI & 0.1 & 45 & 56 & 0.29 & 0.62 \\
\hline XII & 0.35 & 45 & 22 & 0.57 & 0.68 \\
\hline
\end{tabular}

Since the films in Table 5 were of the same thickness, the \%T at $500 \mathrm{~nm}$ was treated using Beer's Law. Upon conversion of \% to absorbance (A), a linear plot was obtained for A vs. wt $\%$ NATSWCNT loading (Figure 8). A linear least squares fit of the LaRCTM CP2 nanocomposite data afforded a correlation coefficient of 0.9975 with a slope of $1.6387(\mathrm{wt} \%)^{-1}$ for a $45 \mu \mathrm{m}$ thickness. Likewise, A at $500 \mathrm{~nm}$ for the ASTAA LaRCTM CP2/NAT-SWCNT nanocomposites (Table 2) was plotted. A linear least squares fit of the ASTAA LaRC ${ }^{\text {TM }}$ CP2 nanocomposite data afforded a correlation coefficient of

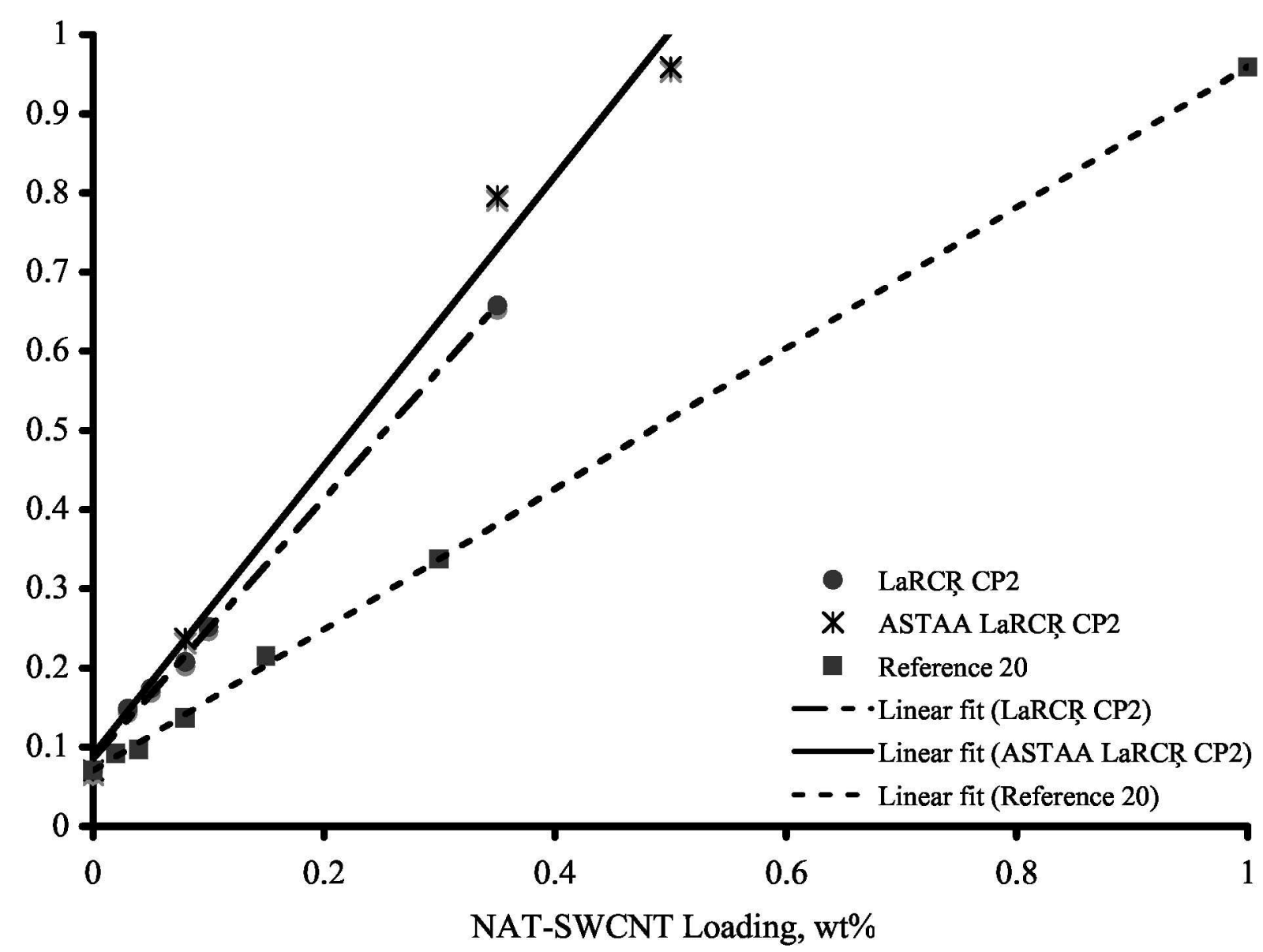

$\mathrm{A}\left(\mathrm{LaRC}{ }^{\mathrm{TM}} \mathrm{CP} 2\right.$ nanocomposite $)=1.6387 \times(\mathrm{NAT}-\mathrm{SWCNT}, \mathrm{wt} \%)+0.0851 \quad \mathrm{R}^{2}=0.9975$ A (ASTAA LaRCTM CP2 nanocomposite) $=1.8285 \times($ NAT-SWCNT, wt $\%)+0.0903 \quad R^{2}=0.9876$ $\mathrm{A}($ Reference 20$)=0.8893 \times(\mathrm{NAT}-\mathrm{SWCNT}, \mathrm{wt} \%)+0.0703 \mathrm{R}^{2}=0.9996$

Figure 8. Plot of Absorbance vs. wt\% NAT-SWCNT loading for NAT-SWCNT nanocomposites. 
0.9975 with a slope of $1.6387\left(w t^{\%}\right)^{-1}$ for a $\sim 45 \mu \mathrm{m}$ thickness. From Figure 8 it is evident that the ASTAA LaRC ${ }^{\text {TM }}$ CP2 nanocomposites exhibited a larger absorbance compared to LaRC ${ }^{\text {TM }}$ CP2 nanocomposites. A number of factors maybe responsible for this absorbance increase including interactions of the NAT-SWCNTs with the silicon dioxide and covalent bonding with the moieties generated from the alkoxysilane endcap. The data from reference 20 was also plotted. It had a correlation coefficient of 0.9996 and a slope of $0.8893(\mathrm{wt} \%)^{-1}$ for the NAT-SWCNTs used in that study for $40 \mu \mathrm{m}$ thick films. A nonzero y-intercept was obtained in all cases and is presumably due to absorption by the neat polymer and scattering and reflection by the film surface(s).

Dividing the slope of the line by the film thickness affords an effective extinction coefficient of 0.036 and $0.038(\mathrm{wt} \% \mu \mathrm{m})^{-1}$ for the LaRC ${ }^{\text {TM }}$ CP2 and ASTAA LaRCTM CP2 nanocomposites, respectively, and $0.022(\mathrm{wt} \% \mu \mathrm{m})^{-1}$ for the materials from reference 20 . The lower effective extinction coefficient of the NAT-SWCNTs of reference 20 is attributed to the debundling effect that was attained by the preparative method. For comparison, the effective extinction coefficient was $0.069(\mathrm{wt} \% \mu \mathrm{m})^{-1}$ for the ASTAA LaRCTM CP2/ HiPco SWCNT nanocomposites. ${ }^{8}$

The $\alpha$ was treated similarly in a Beer's Law-like relationship yielding a linear least squares fit correlation of 0.9711 and 0.9508 for the LaRC ${ }^{\text {TM }}$ CP2 and ASTAA LaRC ${ }^{\text {TM }}$ CP2 nanocomposites, respectively. The ASTAA LaRCTM CP2 nanocomposites exhibited a higher $\alpha$ than LaRCTM CP2 nanocomposites for comparable NAT-SWCNT loadings and may be due to similar reasons as stated above.

Consistent with the ASTAA based SWCNT nanocomposites, the Tg and room temperature thin film tensile properties were unaffected by the NAT-SWCNTs at these low loading levels (Table 6).

Table 6. LaRCTM CP2 Nanocomposite Film Characterization.

\begin{tabular}{|c|c|c|c|c|c|}
\hline & NAT-SWCNT, & Tg, & \multicolumn{3}{|c|}{ Tensile Properties } \\
\cline { 4 - 6 } ID & wt \% & ${ }^{\circ} \mathrm{C}$ & Strength, MPa & Modulus, GPa & Elong., \% \\
\hline VII & 0 & 205 & $102 \pm 3$ & $2.91 \pm 0.11$ & 6 \\
\hline VIII & 0.03 & 204 & $107 \pm 11$ & $3.09 \pm 0.06$ & 5 \\
\hline IX & 0.05 & 205 & $107 \pm 5$ & $3.06 \pm 0.08$ & 4 \\
\hline X & 0.08 & 205 & $106 \pm 10$ & $3.04 \pm 0.17$ & 5 \\
\hline XI & 0.1 & 205 & $105 \pm 0.5$ & $3.09 \pm 0.03$ & 4 \\
\hline XII & 0.35 & 206 & $110 \pm 3$ & $3.14 \pm 0.02$ & 5 \\
\hline
\end{tabular}

\section{CONCLUSIONS}

Pristine (EA) and carboxylic acid functionalized (NAT) SWCNTs that were of similar size distribution and aspect ratio allowed for direct comparison of nanocomposite properties with regards to SWCNT functionalization. The effect of SWCNT functionalization on nanocomposite electrical properties was isolated by characterizing nanocomposites prepared from EA and NAT SWCNTs in reactive ASTAA and inert LaRC ${ }^{\text {TM }} \mathrm{CP} 2$ polyimide polymer matrices. Volume resistivities of LaRC ${ }^{\text {TM }}$ CP2 polyimide nanocomposites prepared with NAT-SWCNTs were at least 3 orders of magnitude lower than analogous compositions prepared from the ASTAA matrix. The main difference between the two nanocomposites was that covalent bonding was possible between the functionalized SWCNTs and the reactive ASTAA matrix; this type of bonding was not possible with the inert LaRCTM CP2 polyimide 
matrix. The best electrical properties were obtained with EA-SWCNTs in the ASTAA matrix. This investigation suggests that although SWCNT functionalization yields improved dispersion in nanocomposites via covalent or hydrogen bonding with the polymer matrix, such functionalization is detrimental to the electrical properties of carbon nanotubes.

The effect of SWCNT functionalization on nanocomposite optical, mechanical and thermal properties was not as significant at the low SWCNT loadings sufficient to yield notable improvements in electrical properties.

The use of trade names or manufacturers does not constitute an official endorsement of such products or manufacturers, either expressed or implied, by the National Aeronautics and Space Administration.

\section{REFERENCES}

1. CHM Jenkins, Gossamer Spacecraft: Membrane and Inflatable Structures Technology for Space Applications, Vol. 191, American Institute of Aeronautics and Astronautics 2001.

2. RE Smith and GS West, compilers. Space and planetary environment criteria for use in space vehicle development, 1982 Revision. vol. 1.Washington, DC, USA: NASA TM 82478; 1982.

3. AS Jursa, editor. Handbook of geophysic and the space environment, Air Force Geophysics Laboratory, Air Force Systems Command USAF, NTIS Document ADA 167000; 1981.

4. The Radiation Design Handbook, ESA PSS-01-609 (draft). Paris:European Space Agency; 1989.

5. KA Watson, FL Palmieri, and JW Connell, Macromolecules, 35, 4968 (2002).

6. SRS Technologies. Huntsville. AL 35806. http://www.stg.srs.com/atd/polyimimidesales lcp prop.htm

7. C Park, Z Ounaies, KA Watson, RE Crooks, JG Smith Jr, SE Lowther, JW Connell, EJ Siochi, JS Harrison, and TL St. Clair, Chem Phys Lett, 364, 303 (2002).

8. JG Smith Jr., KA Watson, JW Connell, DM Delozier, PT Lillehei, Y Lin, B. Zhou, and YP Sun, Polymer, 45, 825-830 (2004).

9. JG Smith Jr., DM Delozier, JW Connell, and KA Watson, Polymer, 45, 6133 (2004).

10. KA Watson, DM Delozier, JG Smith, Jr., and JW Connell, Polymer, 45, 2076 (2005).

11. PJ Glatkowski, P Mack, JL Conroy, JW Piche, P Winsor, US Patent 6,265,466 B1, issued July 24; 2001 to Eikos, Inc.

12. PJ Glatkowski, Sci Adv Mat Proc Eng Proc., $\underline{48}, 2146$ (2003).

13. M Kaempgen, GS Duesberg, and S Roth, Applied Surf. Sci., 252, 425 (2005).

14. N Ferrer-Anglada, M Kaempgen, V Skakalova, U Dettlaf-Weglikowska, and S. Roth, Diamond and Related Matls, 13, 256 (2004).

15. ET Thostenson, Z Ren, and TW Chou, Comp. Sci. and Tech., 61, 1899 (2001).

16. JL Bahr, ET Mickelson, MJ Bronikowski, RE Smalley, JM Tour, Chem. Commun., 2, 193 (2001).

17. H Hu, B Zhao, ME Itkis, and RC Haddon, J. Phys. Chem. B, 107, 13838 (2003).

18. H Hu, A Yu, E Kim, B Zhao, ME Itkis, E Bekyarova, and RC Haddon, J Phys. Chem. B, 109, 11520 (2005).

19. S-M Yuen, C-C M Ma, Y-Y Lin, and H-C Kuan, Comp. Sci. and Tech., doi: 10.1016/j.compscitech.2006.12.006 (2007). 
20. A Yu, H Hu, E Bekyarova, ME Itkis, J Gao, B Zhao, and RC Haddon, Comp. Sci. and Tech., $\underline{66}$, 1187 (2006).

21. C Journet, WK Maser, P Bernier, A Loiseau, M Lamy de la Chappelle, S Lefrant, P Deniard, R Lee, and JE Fischer, Nature, 388, 756 (1997).

22. ME Itkis, D Perea, S Niyogi, J Love, J Tang, A Yu, C Kang, R Jung, and RC Haddon, J. Phys. Chem. B, 108, 12770 (2004).

23. H Hu, A Yu, E Kim, B Zhao, ME Itkis, E Bekyarova, and RC Haddon, J. Phys. Chem. B, 109, 11520 (2005).

24. ME Itkis, D Perea, S Niyogi, S Rickard, M Hamon, H Hu, B Zhao, and RC Haddon, Nano Lett., $\underline{3}$, 309 (2003).

25. B Zhou, ME Itkis, S Niyogi, H Hu, D Perea, and RC Haddon, J. Nanosci. Nanotech., 4, 995 (2004). 